\title{
Letting the affordances fool around: architectural space from the users' point of view
}

\author{
Edward Baggs ${ }^{1 *}$ and Kerstin Sailer ${ }^{2}$ \\ ${ }^{1}$ Rotman Institute of Philosophy, University of Western Ontario, London ON, Canada \\ ${ }^{2}$ Bartlett School of Architecture, University College London, London, United Kingdom \\ * Corresponding author: Edward Baggs, Rotman Institute of Philosophy, University of Western \\ Ontario, 1151 Richmond Street North, London, Ontario, Canada, N6A 5B7 Email: \\ ed.baggs@gmail.com
}

\begin{abstract}
Erik Rietveld's lecture describes the creation of architectural works from the point of view of the architects. We are curious about architectural space as a living system: what happens once the architects have left? We introduce the space syntax notion of virtual community, and suggest that this is compatible with Rietveld's distinction between the field and the landscape of affordances.
\end{abstract}

Keywords affordances; social cognition; space syntax; sociomateriality

"It will serve to show how articulated language comes into being. I let the vowels fool around. I let the vowels quite simply occur, as a cat meows . . . Words emerge, shoulders of words, legs, arms, hands of words. Au, oi, uh." - Hugo Ball, Dada Manifesto, 1916

Professor Rietveld's approach to ecological psychology could be called Dadaist. Others have taken Gibson's affordance concept (Gibson 1979) and have attempted to formalize it-to specify necessary and sufficient conditions that define it (Turvey 1992, Chemero 2003), to operationalize it as a laboratory construct (Warren 1984, Wagman 2020), to mathematize it as a term in a dynamic equation (Fajen 2007, Withagen et al. 2017). These are all fine things for scientists to be looking for. Affordances are in such ways treated as component parts of a system, to be identified and named and dealt with one by one. Rietveld and his colleagues have pursued a different strategy. In the Rietveldian approach, the affordances are allowed to fool around. Rietveld points out that affordances do not typically show up for us one at a time, but 
appear all at once, as a rich set of possibilities. In Rietveld's view, affordances do not admit of a purely component-based analysis. If you want to understand what affordances are, the most sensible thing to do is to play with them.

One of the results of this way of thinking about affordances is the set of artworks presented in the lecture, created by the RAAAF studio. What unifies this series of works is their playful subversiveness. Familiar objects and surfaces are turned into raw material to be re-examined and re-configured. A concrete bunker exists for a specific purpose, which everyone understands: a bunker is an enclosure affording protection from bomb blasts. The Rietveld brothers' response to this is: Let's slice through it and turn it into a gateway-a weightless symbol! Or again, a beach is a surface affording support for humans... Let's turn it into a 12 meter high solid cube! Chairs and desks are artifacts affording sitting and typing... Let's abolish them!

In his lecture, Rietveld focuses on the sociomaterial practices and processes involved in the creation of the artworks. The focus is on the activities of the artist-architects themselves, and the descriptions are illuminating. We would like, however, to invite Professor Rietveld to comment on architectural space as a living system. Architectural spaces can be works of art. But they can also be persisting sociomaterial structures-places for people to inhabit, move through, interact in. Our question is: how might we pursue a Rietveldian analysis of architectural space from the users' point of view?

Look again at Rietveld's Fig. 19-a staged photograph showing people in office attire modeling 'the End of Sitting.' It makes for a provocative image. We suspect, though, that Rietveld would be the first to acknowledge that this setting would make for a lousy office environment in practice.

Let us now consider a real office environment, such as the one shown below. Figure 1 highlights a typical scene of office life, while figure 2 illustrates the outcome of nine rounds of spot sampling, i.e. observing and mapping where people were sitting, standing, moving and interacting. 


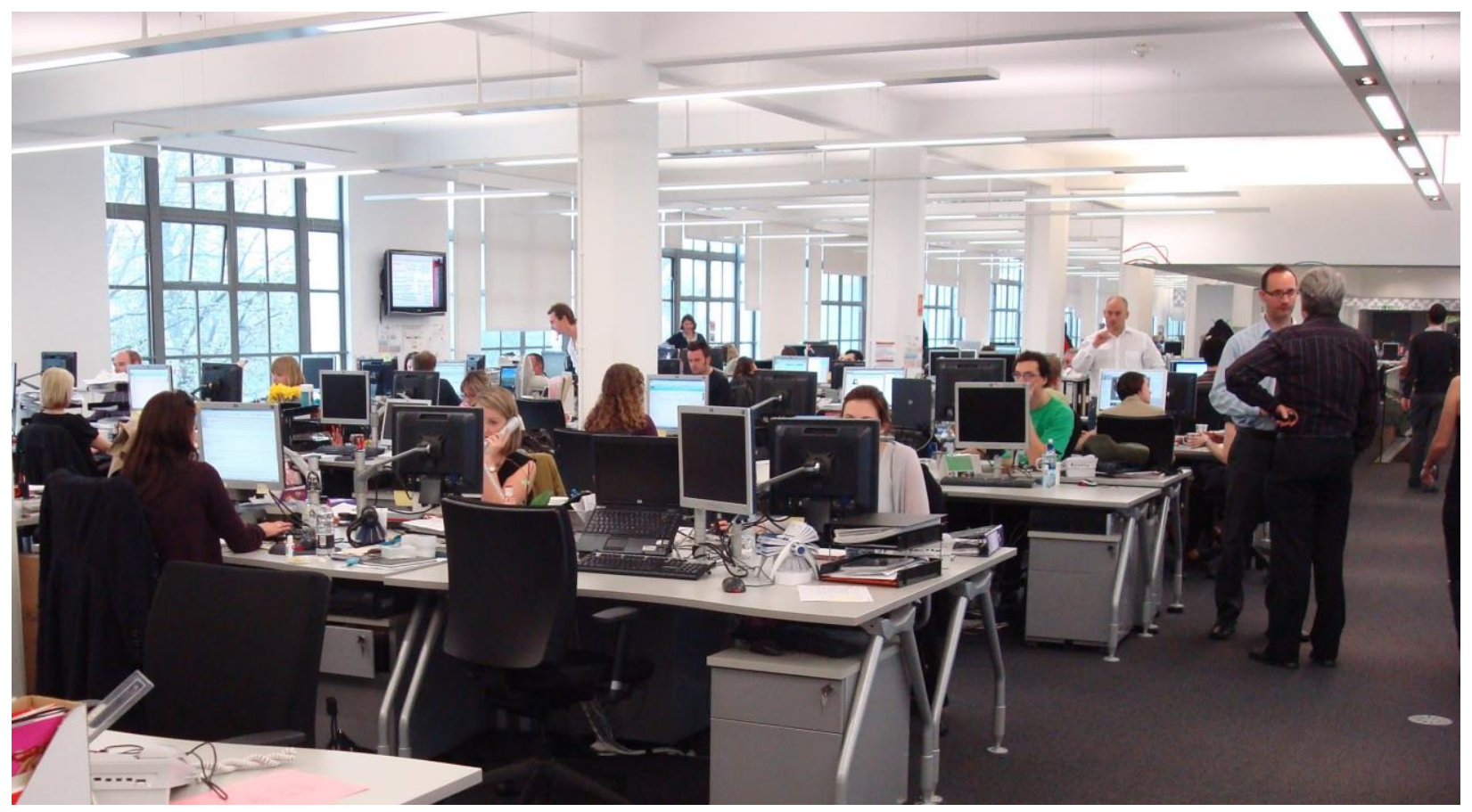

Fig 1: Office life inside a London based media company. Source: Sailer 2010.

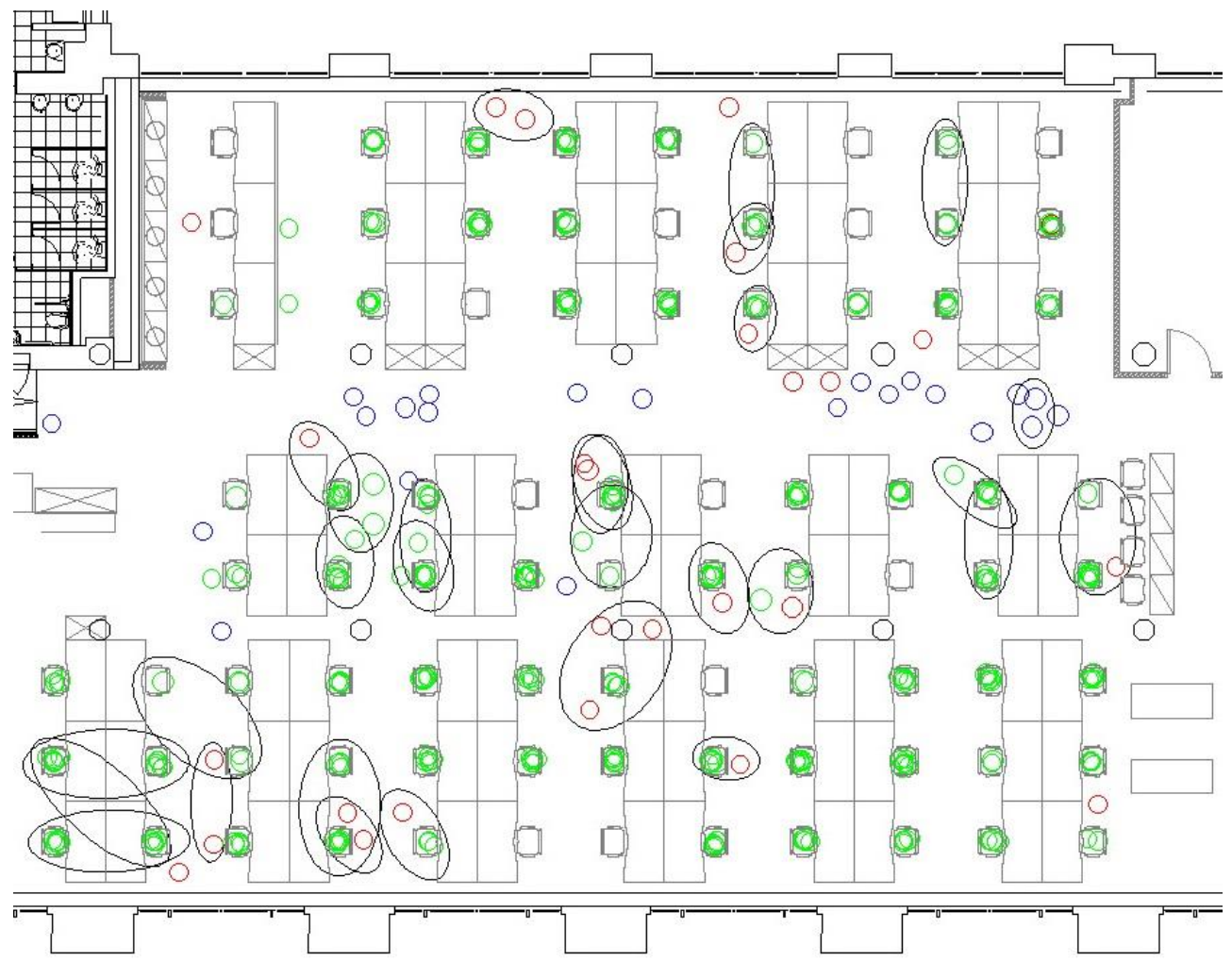

Fig 2: Snapshot of behavioural patterns in a London based media company showing instances of people sitting (green), standing (red), moving (blue) and interacting (black bubbles). Source: Sailer 2010. 
Of the many things that could be pointed out here, we want to focus on the fact that workplaces are social environments. They do not only afford individual postures and activities such as reading, typing, or contemplating, but also collaborative, interactive and social activities, arising from the co-presence of other people. What is striking about Rietveld's Fig. 19 is that each of the actors is immersed in a single private activity: everyone is gazing at a book, a phone, or a laptop. Granted, the installation is designed with a narrow purpose in mind: to illustrate the possibility of adopting unorthodox kinds of individual posture. The installation can therefore hardly be faulted for failing to rethink the office in other ways. But even so. In the photograph no one has so much as a coffee cup or a water bottle nearby. And there are no conversations taking place. Do the users of the space not get to play with multiple affordances at once too?

One tool for getting to grips with the social dimension of architectural space is Bill Hillier's concept of the virtual community. Hillier argues that co-present people act as a social resource and raw material for a potential community, which can be activated if necessary. Importantly, for Hillier, the community exists in potential form even when the individuals are not currently interacting with one another: "even without conversion into interaction, patterns of co-presence are a psychological resource, precisely because co-presence is the primitive form of our awareness of others" (Hillier, 1996: 141). A virtual community, he continues, is the pattern of natural co-presence emanating from a spatial design and its usage processes. We are members of a virtual community simply by being there.

The relationship between a spatial design and patterns of encounter, on this account, is said to be probabilistic (Hillier et al. 1987). Certain arrangements of space-dense or sparse, open or closed, accessible or inaccessible, bringing people together or keeping them apart, mixing groups or separating them-are describable in terms of the interaction patterns that are enabled or made probable by the overall spatial configuration. A particular spatial design tends to tip the scales in one direction or another, and as such it may make encounter patterns between various groups of people more or less likely. This 'field of probabilistic encounter' can be used for reflecting on the affordances that an architectural space presents to its users.

Hillier's notion of a virtual community would appear, on the face of it, to be compatible with the concept of the landscape of affordances developed by Rietveld and his colleagues (Rietveld \& Kiverstein 2014, Bruineberg \& Rietveld 2014, Van Dijk \& Rietveld 2018). By being present in the same space, we constitute part of the standing pattern of possible activities that other individuals can engage in. As individuals, we are simultaneously both in the landscape and a part of the landscape. The landscape is inherently sociomaterial: "there is no social that is not also material, and no material that is not also social" (Orlikowski 2007: 1437; see also Van Dijk \& Rietveld 2018).

The interesting architectural question is why a given configuration of potential encounters gives rise to a given set of actual behaviors once the space is populated with users. Rietveld and colleagues (Bruineberg \& Rietveld 2014, Van Dijk \& Rietveld 2018) distinguish between the landscape of affordances (the entire set of possible activities) and the field of affordances (the set of activities that stand out as relevant to a given actor). What stands out as relevant in an 
individual's field of affordances is firstly influenced by the individual's personal history of learning (Rietveld 2008, Baggs \& Chemero 2020). Secondly, a field of affordances is also shaped in real time in part by what other people around an actor are doing, and by the interactions that unfold between actors (see our Fig. 2). And thirdly, affordances respond to the probability field that architectural space provides, allowing for 'multiplicities of occupation' (Groák 1992) yet realised as patterns where certain actions are more likely than others (Sailer 2019).

The RAAAF strategy of architectural intervention seems to go like this. Step one: make a change-generally a large and playful change - in the material structure of the environment. Step two: give the users free rein to make sense of the newly altered space (see also Rietveld \& Rietveld 2011). The users of the space are invited to join in with the fooling around-they are invited to explore, say, the postural possibilities offered by the surfaces. It looks like fun. Does this strategy of architectural intervention have anything to tell us about how to build functional everyday spaces? What, for instance, would a RAAAF-designed office actually look like? (Presumably it would not look exactly like Rietveld's Fig. 19, and it would also presumably not look like our Fig. 1.) How about a hospital ward, or a train station? Does the Rietveldian analysis of affordances lend itself, ultimately, to a user-centered approach to architectural design? Or is that not the point? Perhaps the point is rather that the users of a space are always, in effect, recruited into the process of creating the space itself? If the latter, we would not disagree. $A u$, oi, uh.

\section{ORCID ID}

Edward Baggs https://orcid.org/0000-0003-3203-1250

Kerstin Sailer: https://orcid.org/0000-0001-6066-7737

\section{Bibliography}

Baggs, E. \& Chemero, A. (2020). The third sense of environment. In Wagman, J. B. \& Blau, J. J. C. (eds), Perception as Information Detection: Reflections on Gibson's Ecological Approach to Visual Perception, pp. 5-20, Taylor \& Francis, New York, NY.

Bruineberg, J. \& Rietveld, E. (2014). Self-organization, free energy minimization, and optimal grip on a field of affordances. Frontiers in Human Neuroscience, 8, 599. doi: 10.3389/fnhum.2014.00599

Chemero, A. (2003). An outline of a theory of affordances. Ecological Psychology, 15(2): 181-195. doi: 10.1207/S15326969ECO1502_5

Fajen, B. R. (2007) Affordance-based control of visually guided action. Ecological Psychology, 19(4): 383-410. doi: 10.1080/10407410701557877

Gibson, J. J. (1979). The Ecological Approach to Visual Perception. Boston, Houghton-Mifflin. 
Accepted for publication in Adaptive Behavior, Dec 2020

Groák, S. (1992). The idea of building. Thought and action in the design and production of buildings. London: E. \& F. N. Spon.

Hillier, B. (1996). Space is the machine. A configurational theory of architecture. Cambridge, Cambridge University Press.. Online at: http://eprints.ucl.ac.uk/3881/

Hillier, B., Burdett, R., Peponis, J., \& Penn, A. (1987). Creating life: Or, does architecture determine anything? Architecture and Behaviour, 3(3), 233-250.

Orlikowski, W. J. (2007). Sociomaterial practices: exploring technology at work. Organization Studies, 28(9), 1435-1448. doi:10.1177/0170840607081138

Rietveld, E. (2008). Situated normativity: the normative aspect of embodied cognition in unreflective action. Mind, 117(468): 973-1001. doi: 10.1093/mind/fzn050

Rietveld, E. \& Rietveld, R. (2011). The paradox of spontaneity and design/Designing spontaneous interactions, Oase, 85: 33-41.

Rietveld, E. \& Kiverstein, J. (2014). A rich landscape of affordances. Ecological Psychology, 26(4), 325352. doi: $10.1080 / 10407413.2014 .958035$

Sailer, K. (2010). The space-organisation relationship. On the shape of the relationship between spatial configuration and collective organisational behaviours. (PhD thesis), Technical University of Dresden, Dresden. Retrieved from http://nbn-resolving.de/urn:nbn:de:bsz:14-qucosa-38427

Sailer, K. (2019). Through the lens of social activities - Understanding space. In F. Geipel \& S. Hansmann (Eds.), Raummaschine. Exploring Manifold Spaces (pp. 118-122). Berlin: Jovis.

Turvey, M. T. (1992) Affordances and prospective control: an outline of the ontology. Ecological Psychology, 4(3): 173-187. doi: 10.1207/s15326969eco0403_3

Van Dijk, L. \& Rietveld, E. (2018). Foregrounding sociomaterial practice in our understanding of affordances: the skilled intentionality framework. Frontiers in Psychology, 7, 1969. doi: 10.3389/fpsyg.2016.01969

Wagman, J. B. (2020). A guided tour of Gibson's theory of affordances. In Wagman, J. B. \& Blau, J. J. C. (eds), Perception as Information Detection: Reflections on Gibson's Ecological Approach to Visual Perception, pp. 130-148, Taylor \& Francis, New York, NY. 
Accepted for publication in Adaptive Behavior, Dec 2020

Warren, W. H. (1984). Perceiving affordances: Visual guidance of stair climbing. Journal of Experimental Psychology: Human Perception and Performance, 10(5): 683-703. doi: 10.1037/0096-1523.10.5.683

Withagen, R. Araújo, D., \& de Poel, H. J. (2017). Inviting affordances and agency. New ldeas in Psychology, 45: 11-18. doi: 10.1016/j.newideapsych.2016.12.002 


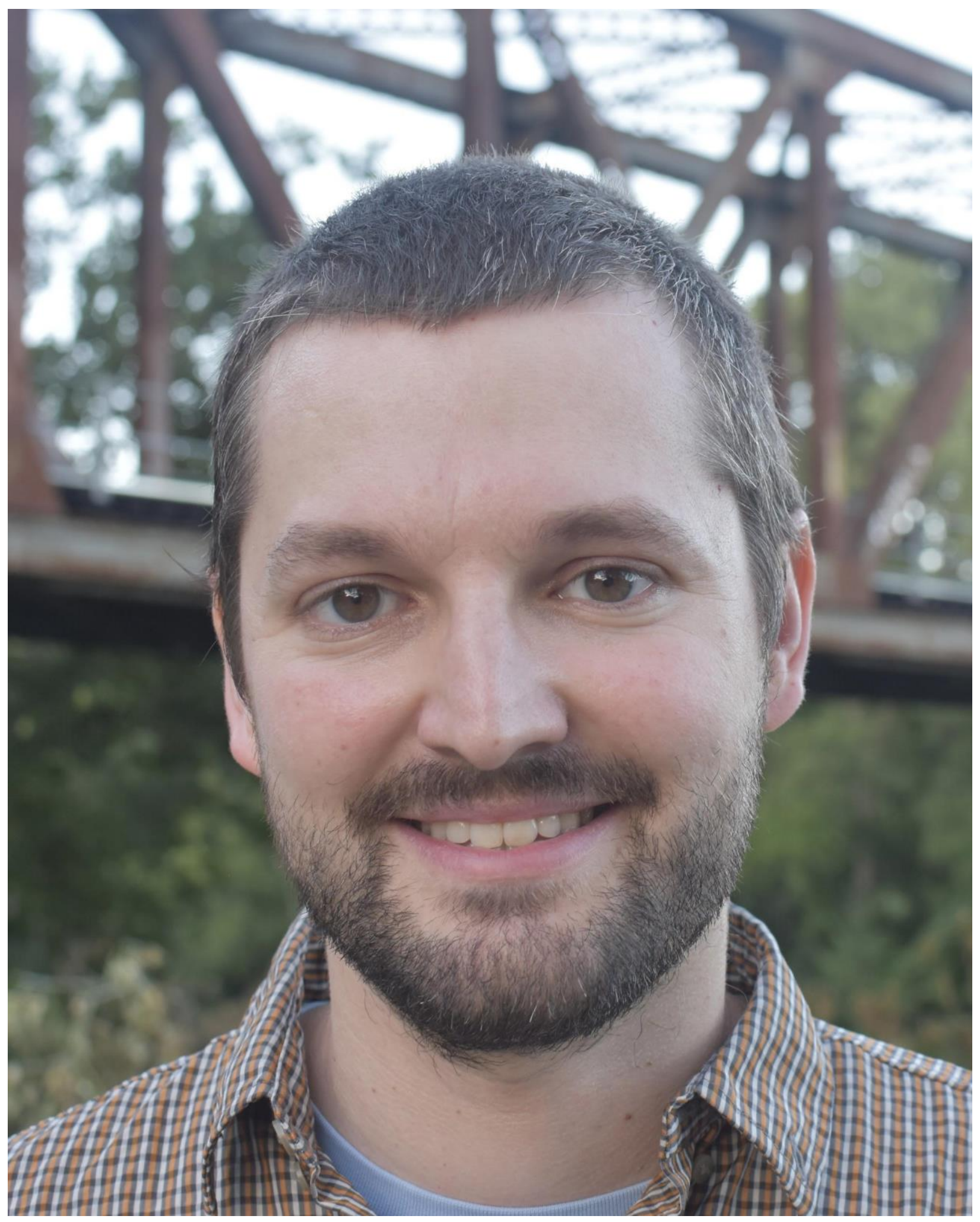

Edward Baggs is a postdoctoral fellow at the Rotman Institute of Philosophy at the University of Western Ontario. He is trying to figure out the conceptual foundations for a radical embodied approach to cognitive science. Sometimes he thinks about traffic infrastructure. 


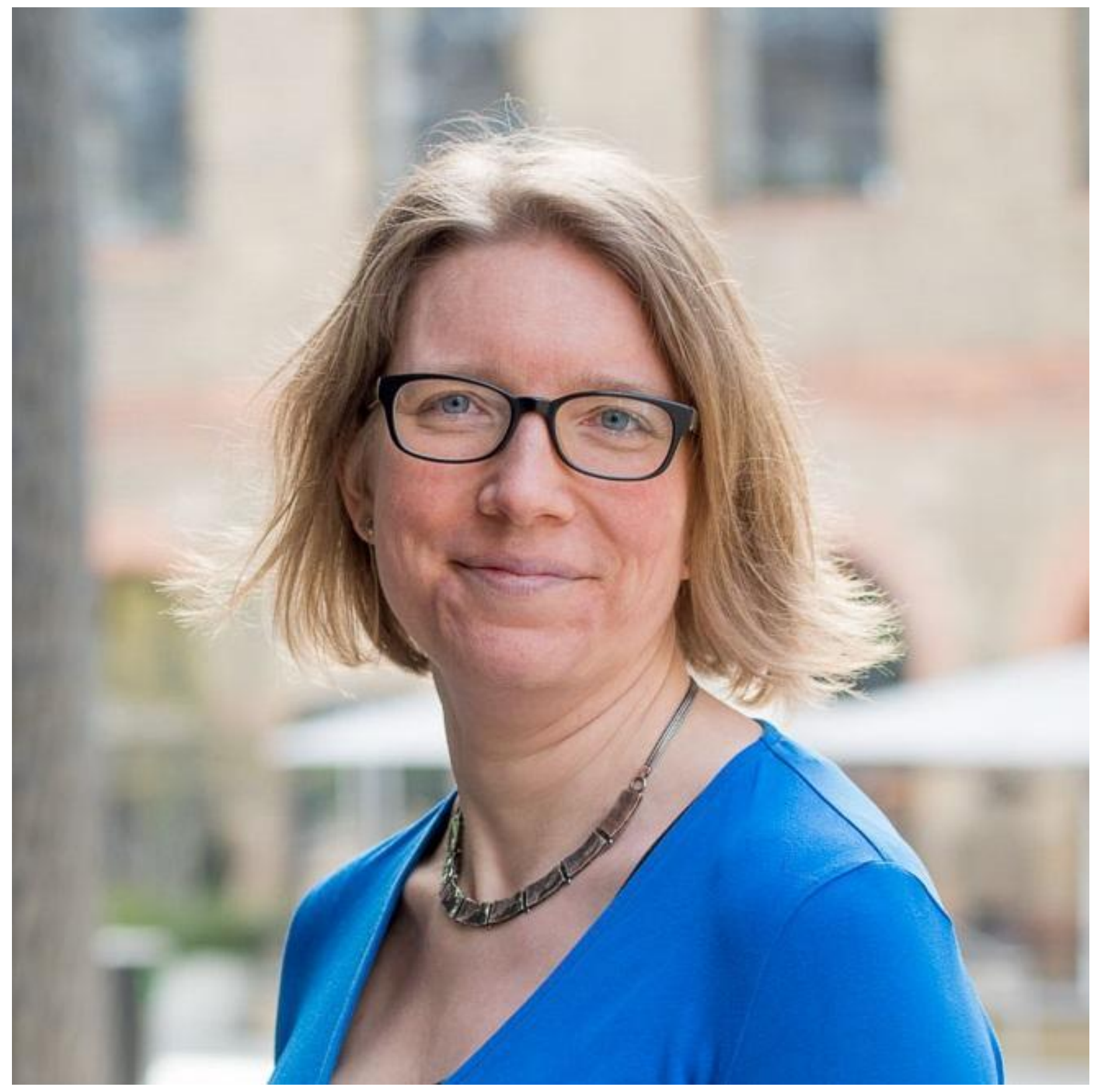

Kerstin Sailer is a Reader in Social and Spatial Networks at the Bartlett School of Architecture at University College London. She investigates the impact of spatial design on people and social behaviours inside a range of buildings such as offices, laboratories, hospitals and schools. An architect by training, her research interests combine complex buildings, workplace environments and space usage with social networks, organisational theory and organisational behaviour. She has authored more than 60 publications across a wide range of journals and conferences in the built environment, sociology, management, network science and computer science domains. 